\title{
Águas Residuárias: uma Alternativa Racional de Reúso
}

\author{
Professor Mestre Delio Guerra Filho (Engenharia Ambiental - UniFOA) \\ delio.guerra@foa.org.br
}

\begin{abstract}
Resumo
Este artigo faz uma abordagem do conceito de reúso de efluentes, das tecnologias disponíveis para a melhor aplicação na obtenção de águas em condições de reutilização. São apresentadas algumas tecnologias aplicadas em vários segmentos industriais e finalmente, são mostradas as diversas combinações dos processos físico-químicos, com destaque os processos oxidativos avançados. Finalmente são mostradas essas tecnologias com ênfase no reúso dos efluentes em indústrias de tingimento têxtil.
\end{abstract}

Palavras chaves - Reúso; águas residuárias; tecnologias, indústria têxtil

\section{Introdução}

A natureza, por meio do ciclo hidrológico, vem reciclando e reutilizando a água há milhões de anos e com muita eficiência.

Durante muitos anos, o ciclo hidrológico funcionou de forma amplamente satisfatória, mas atualmente isto não é mais possível em muitas regiões, face ao agravamento das condições de poluição, resultado basicamente da falta de tratamento adequado dos efluentes gerados pelos setores produtivos e do crescimento urbano.

Para que a produção industrial seja integrada ambientalmente, ela deverá possuir dois aspectos: um ecológico que relaciona o trabalho com a natureza, e um econômico, que trata do trabalho com a sociedade. Para tanto, deve-se criar estratégias e opções técnicas, desenvolvendo e selecionando alternativas de reúso dos efluentes, implementando planos de reúso, bem como medindo os sucessos alcançados.

$\mathrm{Na}$ fabricação de um determinado produto, não há nenhum processo químico que venha resultar num só produto, também são gerados resíduos indesejáveis como: gases, líquidos ou partículas sólidas. Devido a isto, hoje nos deparamos com uma preocupação pública crescente sobre a qualidade do ambiente, a medida que se verifica um aumento na edição de legislação ambiental. Muitas indústrias químicas estão buscando alternativas para minimizar o uso de recursos hídricos e a geração de efluentes. Sendo hoje um desafio e uma necessidade para todos os envolvidos nas indústrias a reutilização dos efluentes gerados.

Podemos dizer que há uma variedade de razões para cada setor produtivo procurar minimizar a geração de efluentes. Com o desenvolvimento tecnológico, novas técnicas são colocadas a disposição no mercado e devem ser estudadas as suas aplicações, quer independente ou não.

\section{Conceito de Reúso}


A reutilização ou reúso de água ou o uso de águas residuárias, não é um conceito novo e tem sido praticado em todo o mundo há muitos anos.

As águas utilizadas tanto para o consumo humano como para as atividades sócioeconômicas são retiradas de rios, lagos, represas e aqüíferos também conhecidos como águas interiores.

O reúso de água nas indústrias está ganhando importância devido à competição crescente entre elas e a normas ambientais cada dia mais severa. A água já não é vista como um bem gratuito. Devido ao grande crescimento da industrialização, aliado ao problema da escassez de água potável, há um aumento na demanda do consumo de água tratada para uso nas indústrias, provocando também um aumento da necessidade de seu reúso.

O reúso de água residuária subentende em uma tecnologia desenvolvida e adaptada, em maior ou menor grau, de acordo com os fins a que se destina e como ela foi utilizada anteriormente. Tecnologias modernas e inovadoras, juntamente com a modificação e/ou adaptação das tecnologias existentes estão tornando comercialmente disponíveis para reduzir consumo de água nos processos industriais.

\section{Potencial de Reúso}

Rouse (2003) incentiva e defende que "ao invés de diluir e destruir, a ordem é reusar".

Esta reutilização já acontece espontaneamente na própria natureza, no ciclo hidrológico, ou mesmo, de forma planejada, através da ação humana. O reúso da água pode ser feito para fins potáveis ou não potáveis. Pode ser utilizada para inúmeros fins, tais como, geração de energia, refrigeração de equipamentos, em diversos seguimentos industriais, em prefeituras e entidades que usam a água para lavagem de ruas e pátios, para irrigação, recarga de lençol freático, desobstrução de rede de esgotos e/ou de águas pluviais bem como em lavagem de veículos.

A reutilização da água pode ser direta ou indireta, decorrentes de ações planejadas ou não, de acordo com a Organização Mundial da Saúde, conforme citado por Mancuso e Santos (2003):

- Reúso indireto não planejado da água: ocorre quando ela é utilizada em alguma atividade humana, é descarregada no meio ambiente e novamente utilizada a jusante, em sua forma diluída, de maneira não intencional e não controlada. Caminhando até o ponto de captação para o novo usuário, a mesma está sujeita às ações naturais do ciclo hidrológico (diluição, autodepuração).

- Reúso indireto planejado da água: ocorre quando os efluentes, depois de tratados, são descarregados de forma planejada nos corpos de águas superficiais ou subterrâneas, para serem utilizadas a jusante, de maneira controlada, no atendimento de algum uso benéfico.

- Reúso direto planejado das águas: ocorre quando os efluentes, depois de tratados, são encaminhados diretamente de seu ponto de descarga até o local do reúso, não sendo descarregados no meio ambiente. É o caso com maior ocorrência, destinando-se a uso em indústria ou irrigação.

- Reciclagem interna: é o reúso da água internamente às instalações industriais, tendo como objetivo a economia de água e o controle da poluição.

Quanto a classificação das águas, que está intimamente ligado ao reúso, existe uma Resolução do Conama, a de $n^{\circ} 357$ (2005), que divide a água em três categorias mais 
abrangentes: doces, salinas e salobras. Esta divisão leva em conta ainda treze classes, cinco para as águas doces (classe especial, 1, 2, 3 e 4); quatro para águas salinas (classe especial, 1, 2 e 3) e quatro para águas salobras (classe especial, 1, 2 e 3). As águas para o reúso industrial podem ser originadas de quaisquer das classes mencionadas, pois dependem apenas do fim a que se destinam. Os parâmetros físico-químicos para cada classe estão bem definidos na referida Resolução. Sendo assim, podemos dizer que a classificação das águas aponta os seguintes objetivos:

- Assegurar às águas qualidade compatível com os usos mais exigentes a que forem destinados;

- Determinar a possibilidade de usos menos exigentes por meio de reúso;

- Diminuir os custos de combate e controle à poluição das águas, mediante ações preventivas permanentes, inclusive por meio do reúso.

Para o reúso de águas residuárias numa indústria, Martins e Almeida, (1999) lembram que faz-se necessário o conhecimento das características físico-químicas das mesmas, de modo a definir novas utilizações, atendendo aos parâmetros pré-definidos no processo produtivo. Isto posto, as análises das águas residuárias tornam-se imprescindíveis, a fim de se avaliar a sua qualidade logo após o descarte e a necessidade de tratamento antes da sua reutilização.

A Fiesp/Ciesp (2004), em seu manual de conservação e reúso, destaca os benefícios de adoção dessa prática:

a) Benefícios Ambientais:

- Redução do lançamento de efluentes industriais em cursos d'água, possibilitando melhorar a qualidade das águas interiores das regiões mais industrializadas do Estado de São Paulo;

- Redução da captação de águas superficiais e subterrâneas, possibilitando uma situação ecológica mais equilibrada;

- Aumento da disponibilidade de água para usos mais exigentes, tais como abastecimento público, hospitalar, etc.

b) Benefícios Sociais:

- Ampliação da oportunidade de negócios para as empresas fornecedoras de serviços e equipamentos, e em toda a cadeia produtiva;

- Ampliação na geração de empregos diretos e indiretos;

- Melhoria da imagem do setor produtivo junto à sociedade, com reconhecimento de empresas socialmente responsáveis.

c) Benefícios Econômicos:

- Conformidade ambiental em relação a padrões e normas ambientais estabelecidos, possibilitando melhor inserção dos produtos brasileiros nos mercados internacionais;

- Mudanças nos padrões de produção e consumo;

- Redução dos custos de produção;

- Aumento da competitividade do setor;

- Habilitação para receber incentivos e coeficientes redutores dos fatores da cobrança pelo uso da água.

Hespanhol (2004) aponta que em áreas de concentração industrial significativa, as aplicações industriais da água apresentam grandes possibilidades de serem reusadas. Estas são basicamente as seguintes: 
- Em torres de resfriamento como água de "make-up";

- Nas caldeiras;

- Na construção civil, incluindo a preparação e a cura de concreto, e para a compactação do solo;

- Na irrigação de áreas verdes das instalações industriais, nas lavagens de pisos e para alguns tipos de peças, principalmente na indústria mecânica;

- Em processos industriais.

\section{Tecnologias Disponíveis}

Na figura 1 são mostrados os principais estágios de tratamento de águas residuárias destacando algumas tecnologias disponíveis segundo Mujeriego e Asano (1999). Podemos observar que tais processos tecnológicos devem ser aplicados em conjunto, de acordo com a necessidade de reúso.

\section{1. Filtros Biológicos}

Estruturalmente são feitos de concreto, na maioria das vezes, contendo em seu interior um leito formado de pedras e/ou plásticos. O efluente, ao passar no seu interior, propicia o crescimento de uma população microbiana que acumula sobre este leito, no qual sobrevive aerobicamente, consumindo a matéria orgânica presente. Na falta da matéria orgânica, esses microrganismos morrem e desprendem deste leito, sendo retidos em um decantador localizado a seguir. Se cuidadosamente operado e monitorado o seu filtrado pode ser reusado em casos em que a demanda bioquímica do oxigênio solúvel não seja um parâmetro crítico afirma Mancuso e Santos (2003).

\section{4 . 2. Processo de Lodo Ativado}

Mundialmente utilizado para o tratamento de despejos domésticos e industriais, onde há um elevado volume de efluentes e uma área reduzida. Requer uma operação sofisticada e um consumo de energia elétrica maior. Basicamente, é composto de um reator, um tanque de decantação e um sistema de recirculação do lodo. No reator ocorrem as reações bioquímicas de remoção da matéria orgânica e, em alguns casos, da matéria nitrogenada (von Sperling, 2002). As principais variantes desse processo são:

- Idade do lodo

- Tipo de fluxo (contínuo ou intermitente)

- Origem do efluente (esgoto bruto, do decantador primário, do reator anaeróbico ou de outro tratamento biológico).

\section{4 . 3. Processo de Coagulação, Floculação e Sedimentação}

Consiste na remoção de sólidos e na precipitação de compostos pela adição de produtos químicos, seguidos de uma mistura rápida para dispersá-los e uma mistura mais lenta para promover a formação de flocos sedimentáveis na unidade de decantação (Mancuso 
e Santos, 2003). Os produtos químicos podem ser aplicados em diversos pontos do processo de tratamento para remoção da matéria inorgânica e orgânica solúveis ou em suspensão. Tais produtos podem ser divididos em 4 categorias: cal, sais de alumínio, sais de ferro e polímeros. A escolha depende do objetivo da remoção, do $\mathrm{pH}$ e podem ser aplicados juntos ou em separado. Particularmente, a coagulação química é recomendada para efluentes de baixos teores de fósforo, de sólidos em suspensão e demanda bioquímica de oxigênio. A escolha do coagulante e do polímero depende de cada tipo de reúso e das características de cada sistema de tratamento.

\section{4 . 4. Tratamento com Ozônio}

Com base no alto potencial de oxidação do ozônio (2,07 V), o poderoso desinfetante de ação não seletiva e bastante instável, pois apresenta um aspecto positivo, que é acrescentar oxigênio dissolvido ao meio, e uma conotação negativa por não permitir a sua estocagem.

O ozônio; pode reagir com muitas espécies de contaminantes que possuem duplas ligações, tipo $\mathrm{C}=\mathrm{C}, \mathrm{C}=\mathrm{N}, \mathrm{N}=\mathrm{N}$, etc. Também pode oxidar íons, tipo sulfetos, onde seu mecanismo requer apenas seu contato com o ozônio (Gogate e Pandit, 2004).

Existem vários métodos de geração de ozônio, o mais viável tem sido por descargas elétricas em ar seco ou oxigênio (Mancuso e Santos, 2003). Após sua geração, ele é emulsionado na água, onde sua eficiência pode ser aumentada quando se usa difusores porosos. É indicado em sistemas de reúso onde é desejável um alto índice de desinfecção, como também, o controle de compostos organoclorados.

\section{4 . 5. Adsorção em Carvão Ativado}

Mancuso e Santos (2003) recomendam no tratamento avançado de esgotos a remoção de materiais orgânicos solúveis que não foram eliminados nos processos anteriores. O carvão ativado pode ser aplicado sob a forma granular e/ou em pó. Geralmente, é aplicado logo após a filtração e/ou a cloração no ponto de ruptura, minimizando a possibilidade de crescimento de bactérias anaeróbicas em sua superfície. Seu uso tem sido adotado em diversas fases do tratamento, como após o tratamento biológico por lodo ativado para remoção de matéria orgânica e/ou tóxicas, ou após tratamento físico-químico por coagulação, floculação, sedimentação e filtração.

\section{4 . 6. Processo de Troca Iônica}

Basicamente consiste na troca seletiva dos íons de amônio presentes em uma resina mineral pelos íons de cálcio, magnésio e sódio. Deve ser aplicada após uma pré-decantação e/ou filtração, usando um leito de até $2,5 \mathrm{~m}$ de espessura, a uma velocidade de $24-30$ $\mathrm{cm} /$ minuto. A troca seletiva produz um efluente com alto nível de remoção de nitrogênio amoniacal, sendo, portanto, indicado para aplicações de reúso, onde se deseja baixas concentrações desse contaminante e de sólidos dissolvidos totais como descrito por Mancuso e Santos (2003).

\section{4 . 7. Processos de Separação por Membrana}


Consiste na separação de duas soluções, utilizando um filme que atua como barreira seletiva para o transporte dos seus componentes, quando aplicado algum tipo de força motriz externa. A classificação das membranas e as suas principais características estão mostradas na tabela 1. No mecanismo de separação por membranas deve considerar a sua morfologia física

\begin{tabular}{lcccc}
\hline Membrana & Porosidade & Pressão (bar) & Rendimento & Material retido \\
\hline Microfiltração(MF) & $0,1-0,2 \mu \mathrm{m}$ & $<2$ & $90-100 \%$ & $\begin{array}{c}\text { Protozoários, } \\
\text { bactérias, vírus, } \\
\text { partículas }\end{array}$ \\
\hline Ultrafiltração(UF) & $1000-100000 \mathrm{Da}$ & $2-10$ & $90 \%$ & $\begin{array}{c}\text { Material removido } \\
\text { na MF + colóides + } \\
\text { totalidade de vírus }\end{array}$ \\
\hline Nanofiltração(NF) & $200-1000 \mathrm{Da}$ & $5-40$ & $80-90 \%$ & $\begin{array}{c}\text { Íns divalentes e } \\
\text { trivalentes, } \\
\text { moléculas } \\
\text { orgânicas }>\text { que a } \\
\text { sua porosidade }\end{array}$ \\
\hline Osmose reversa (OR) & $<200 \mathrm{Da}$ & $8-200$ & $\begin{array}{c}\text { Efluente } \\
\text { secundário } 65- \\
85 \%\end{array}$ & $\begin{array}{c}\text { Íns, praticamente } \\
\text { toda matéria } \\
\text { orgânica }\end{array}$ \\
\hline
\end{tabular}

Tabela 1 - Tipos de membranas e suas características (adaptada de Schneider e Tsutiya, 2001)

e a natureza química, lembram Mancuso e Santos (2003), como por exemplo, o efeito do peneiramento, ou seja, o tamanho dos poros. O efeito da diferença de solubilidade e capacidade de difusão das substâncias na membrana; decorrentes das diferenças de cargas das espécies que estão sendo separadas, isto é, o efeito eletromecânico. Quanto ao seu aspecto construtivo, podem ser de materiais sintéticos inorgânicos e sintéticos orgânicos. Quanto a sua configuração geométrica básica podem ser de folhas planas e cilíndricas, tais como, tubulares ou de fibras ocas conforme recomenda Schneider e Tsutiya (2001).

\section{4 . 8. Eletrofloculação}

Trata-se de um processo eletroquímico baseado na geração de bolhas de gás, geralmente, $\mathrm{O}_{2}$ e/ou $\mathrm{H}_{2}$ definido por Pascal e Tremiliose-Filho (2005), as quais substituem os aditivos floculantes, portanto, não ocorrendo a adição de agentes floculantes. $\mathrm{O}$ processo consiste basicamente em quatro etapas:

- geração de pequenas bolhas de gás;

- contato entre as bolhas e as partículas em suspensão;

- adsorção das pequenas bolhas de gás na superfície das partículas;

- ascensão do conjunto partículas/bolhas para a superfície.

A geração anódica in situ de bolhas de oxigênio provocam a floculação das partículas em suspensão presentes, que facilmente poderão ser recuperadas. Um eletrodo de $\mathrm{PbO}_{2}$ exibe condições adequadas para promover este processo por apresentar alta estabilidade em elevados potenciais anódicos, além de ser um bom material para gerar oxigênio molecular e oxidar compostos orgânicos.

Assim, toda a matéria em suspensão é eletroflotada, provocando o clareamento do líquido tratado. Na superfície, forma-se uma camada de espuma que contém as partículas flotadas para serem removidas.

\section{Tecnologias Desenvolvidas para Reúso}


Pesquisas realizadas por Adin (1999) mostraram a influência dos agentes coagulantes, cloreto férrico e do sulfato de alumínio, na redução da turbidez e das partículas coloidais formados no tratamento terciário com objetivo de reúso industrial. Ele concluiu que o tamanho da partícula e a turbidez dependem do $\mathrm{pH}$ do meio e da dosagem aplicada que variou de $5-50 \mathrm{mg} / \mathrm{L}$. A taxa de remoção é praticamente igual para os dois agentes coagulantes. $\mathrm{E}$ que o conhecimento da distribuição do tamanho das partículas facilita a implantação do projeto e na especificação do filtro a ser usado.

Estudos de reúso da água de refrigeração, em Taiwan, realizados por You et al (1999), mostrando algumas dificuldades de aplicação de tecnologias de conservação, para cada tipo de indústria. Neste trabalho, foram analisadas as indústrias petrolíferas, siderúrgicas, têxteis, alimentos, termoelétricas e de eletrônicos, onde observaram que em cada caso, os índices de qualidade das águas foram usadas para avaliar as condições operacionais dos sistemas de águas de refrigerações. Algumas aproximações tecnológicas foram propostas, associadas ao fator econômico, ao meio ambiente e à política, como uma referência para as indústrias e para as autoridades governamentais.

Yalcin et al (1999) estudaram, em escala piloto, o efluente de uma indústria de papel ondulado com objetivo de reúso. Após o tratamento anaeróbico e aeróbico dos efluentes, três diferentes tipos de membranas aplicadas em dois estágios, ultrafiltração seguida da osmose reversa, foram comparadas. As membranas de osmose reversa utilizadas foram do tipo para água do mar e outra para águas salinas, ambas da empresa Filmetech. Suas características foram: área de $2 \mathrm{~m}^{2}$, a pressão de operação variou de 4 a 70 bar, uma vazão $23 \mathrm{~L} / \mathrm{min}$, para uma faixa de $\mathrm{pH}$ de 2,0 a 11,0 e uma temperatura máxima operacional de $50{ }^{\circ} \mathrm{C}$. As características do efluente foram: demanda química de oxigênio (DQO) de 2500 a $3500 \mathrm{mg} / \mathrm{L}$; pH de 6,0 a 7,0, condutividade de 6000 a $6700 \mu \mathrm{S} / \mathrm{cm}$ e cor de 3000 a 3500 unidade de Pt.Co. Os resultados alcançados foram uma remoção de 98 a 99 \% da DQO, da cor e condutividade, quando aplicado uma pressão de 55 bar e usando uma ultrafiltração, seguida da membrana osmótica de água do mar. Com este sistema, $60 \%$ da água de processo pode ser reciclada.

O reúso dos efluentes de um complexo petroquímico da Eslovênia foi estudado por Zbontar e Glavic (2000) onde aplicaram a recirculação interna das águas, oriunda do processo de fabricação do metanol. Também reutilizaram a água oriunda do processo de formaldeído na unidade de fabricação de resina sintética. Depois de fazerem pequenas adaptações no processo, através de correções do $\mathrm{pH}$ e da temperatura, conseguiram uma redução no consumo de água de $7 \%$, o equivalente a $11,2 \mathrm{~m}^{3} / \mathrm{h}$.

Madwar e Tarazi (2002) apontam o uso e as vantagens da tecnologia de desalinização em alguns seguimentos industriais, tais como: geração de energia, fábrica de vidros, indústria eletrônica, indústria têxtil, indústria da construção, metal/metalurgia e de papel e celulose. Segundo eles, o reúso das águas residuárias requerem parâmetros de qualidade específicos que só podem ser alcançados usando técnicas como a da dessalinização.

Processos eletroquímicos e de coagulação química são muitos usados para remover a cor, a turbidez (NTU) e a demanda química de oxigênio (DQO) de águas residuárias. Enquanto a troca de íons é empregada para reduzir a DQO, abaixar a concentração de íons ferro, a condutividade e a dureza total dos efluentes conforme vistos em Lin e Chen (1997).

O potencial de reúso industrial de água na Jordânia foi estudado por Mohsen e Jaber (2002) onde avaliaram os tipos de poluentes, bem como as tecnologias para tratamento das águas residuárias. Num total de trinta indústrias foram analisadas. Os efluentes dessas indústrias foram calculados em, aproximadamente, $10.200 \mathrm{~m}^{3} /$ dia. Neste trabalho foi apontado que a substituição da matéria prima e auxiliar, a economia de água e de energia, a recirculação de água, a recuperação de produtos químicos, a melhoria no controle de processo e a minimização dos efluentes, tudo isto, em partes, contribui para a redução do consumo de água. Eles mostram que uma unidade de tratamento de efluentes para 19 indústrias, que geram 
cerca de $5.800 \mathrm{~m}^{3} /$ dia, através de tratamento químico podem recuperar vários metais, tais como: cromo, zinco, cobre, chumbo, níquel, cádmio, estanho, ferro e alumínio, além da água para o reúso na irrigação e nas próprias empresas. Sugeriram ainda a instalação de medidores de vazão, o pagamento pela geração das águas residuárias e a inclusão de tecnologias limpas que minimizariam a falta de água.

Águas residuárias, oriundas do tratamento primário, de uma unidade industrial foram estudadas por Abdessemed e Nezzal (2002) com o objetivo de reúso. Eles usaram como coagulante o $\mathrm{FeCl}_{3}, 120 \mathrm{mg} / \mathrm{L}$, em um $\mathrm{pH}$ ótimo de 5,5 corrigido com solução $0,1 \mathrm{~N}$ de $\mathrm{HCl}$. Logo após adicionaram carvão ativado, de densidade de $0,41 \mathrm{~g} / \mathrm{cm}^{3}$, com uma área de 600 $800 \mathrm{~m}^{2} / \mathrm{g}$ e granulometria de $85 \%$ passando em peneira de $20 \mu \mathrm{m}$. Depois de um certo tempo de contato foi feita a ultrafiltração, usando uma membrana tubular inorgânica (CARBOSEP M5 de $10 \mathrm{kDa}$ e M2 de $15 \mathrm{kDa}$ ), constituída de poros de carbono e camadas de $\mathrm{ZrO}_{2}$, com uma diferença de pressão de 1 bar e uma velocidade de fluxo de $3 \mathrm{~m} / \mathrm{s}$. O resultado apresentou uma redução na turbidez de 90 NTU para zero e a demanda química de oxigênio foi reduzida de $165 \mathrm{mg} / \mathrm{L}$ para $7 \mathrm{mg} / \mathrm{L}$, usando o processo combinado, coagulação-adsorção-ultrafiltração.

Estudos realizados por Marcucci e Tognotti (2002), em escala piloto, nos efluentes de uma montadora de motocicletas, misturados ao esgoto doméstico municipal, levou a uma economia de $5.000 \mathrm{~m}^{3} /$ dia de água na empresa. Após tratamento físico-químico desses efluentes, eles apresentaram duas alternativas:

- tratamento com ozônio seguido de filtragem em carvão ativado;

- aplicação de apenas uma ultrafiltração.

A água antes de chegar ao consumidor final, passou pelo processo de osmose reversa e finalmente por uma estripagem com ar. O ozônio usado foi gerado numa taxa de $2-50 \mathrm{~g} / \mathrm{h}$ e injetado a uma pressão de 12 bar, tendo por objetivo a redução da cor, do odor e de compostos oxidáveis, como ferro e manganês. No filtro de carvão ativado foi aplicado uma velocidade de filtração de $7,5 \mathrm{~m}^{3} / \mathrm{h} . \mathrm{m}^{2}$ e uma pressão de 2 bar; tendo como objetivo a retirada do ozônio remanescente além de reduzir a turbidez e melhorar a cor. No teste da ultrafiltração foi usada uma área filtrante de $18 \mathrm{~m}^{2}$, uma pressão de 5 bar, membrana com uma porosidade de $0,2 \mu \mathrm{m}$. Com a ozonização houve uma redução total da cor e a DQO atingiu valores satisfatório para o reúso. $O$ teste da ultrafiltração apresentou o melhor resultado após 40 horas, com uma permeabilidade de $100 \mathrm{~L} / \mathrm{h} \mathrm{m}^{2}$ e com um reaproveitamento de $90 \%$ da água.

A extração de metais pesados, tais como o cromo, das águas de resfriamento de indústrias de petroquímica, citada por Mirbagheri e Hosseini (2005), foi alcançada pela conversão do cromo de hexavalente para cromo trivalente. A conversão máxima aconteceu na faixa de $\mathrm{pH}$ de 2,0 a 2,3, ajustado por sulfato ferroso e ácido sulfúrico. Já a precipitação máxima do $\mathrm{Cr}(\mathrm{III})$ aconteceu a um $\mathrm{pH} 8,7$ com adição de $\mathrm{Ca}(\mathrm{OH})_{2}$, seguida de agitação e 2 horas de sedimentação. No final, a concentração de cromo foi reduzida de $30 \mathrm{ppm}$ para 0,01 ppm. No caso de cobre que é encontrado na forma de cobre-amônio devido ao efluente oriundo da planta amônia, onde foi observado que a presença de amônia previne a sua precipitação. Então, o teor de amônia presente foi reduzido por aeração. A taxa de aeração ótima alcançada foi de $70 \mathrm{~L} / \mathrm{min}$ e foi constatado que a concentração de amônia alcançou equilíbrio depois de $5,0 \mathrm{~h}$. $\mathrm{O}$ pH ótimo para a precipitação máxima de cobre foi de aproximadamente 12,0, para tanto foi usado a cal. Após a coagulação com a cal e decorrer $2 \mathrm{~h}$ de sedimentação seguida por uma filtração, a concentração do cobre reduziu de $48,51 \mathrm{mg} / \mathrm{L}$ para $0,694 \mathrm{mg} / \mathrm{L}$,

Suthanthararajan et al (2004) estudaram o efluente de uma indústria de couro, onde usaram uma conjugação de tecnologias. Empregaram filtro de areia mais oxidação fotoquímica a $540 \mathrm{~nm}$, seguida de um abrandamento químico, microfiltração em carbono 
ativado, nanofiltração e uma filtração por osmose reversa, conseguiram uma remoção de 98 \% dos sólidos totais dissolvidos e um reaproveitamento de $78 \%$ do efluente. Observaram que a osmose reversa pode retirar $94-98 \%$ dos íons sódio e cloreto presentes e com a nanofiltração consegue uma eficiência de remoção de $55 \%$ de cálcio, $65 \%$ do magnésio. Concluíram, ainda, que a combinação da osmose reversa com a nanofiltração melhora a vida da membrana e aumenta sua permeabilidade. A água obtida pode ser reusada no acabamento do curtume e os resíduos gerados foram encaminhados para as panelas de evaporação solar.

Saha, Balakrisham e Batra (2004) citam que o reúso de água residuária em indústria de papel e celulose e nas usinas açucareiras podem chegar até $75 \%$ a $93 \%$, respectivamente, dependendo da tecnologia a ser utilizada.

Baseado em testes de bancada, usando reatores com fluxo fino, Bousselmi, Geissen e Shroeder (2004) construíram fotoreatores solar areados, em cascata e em escala piloto. Para uma área de $50 \mathrm{~m}^{2}$, trataram água residuária oriunda de uma indústria têxtil, a uma vazão de 1 $\mathrm{m}^{3} / \mathrm{h}$ de. Neste estudo a cinética de degradação foi obtida. Eles demonstraram que o uso da tecnologia catalítica solar pode remover compostos recalcitrantes, assim como a cor. Porém, sua otimização não foi realizada para viabilizar o reúso deste efluente.

Mohsen (2004) mostra que na Usina Termoelétrica Al Hussein, na Jordânia, uma unidade de tratamento de efluentes, onde ocorre um aumento da salinidade devido à evaporação, com capacidade de tratar $55 \mathrm{~m}^{3} / \mathrm{h}$, usando osmose reversa seguida de uma troca de íons, processa $30 \%$ do esgoto doméstico e industrial da região. Após este tratamento, a água obtida pode ser reusada em várias unidades da usina.

O Sistema Fiesp/Ciesp (2004) relaciona às principais tecnologias de tratamento disponíveis, no caso do uso da água para fins industriais, e que possui uma base de dados bastante extensa, assim como uma ampla variedade de equipamentos e sistemas de tratamento de água, os quais são capazes de produzir água com os diversos níveis de qualidade. Desta forma, verifica-se que a questão relacionada ao tratamento de água e efluentes, para uso industrial, não é uma condição limitante para o desenvolvimento de iniciativas que visam promover o uso racional deste recurso.

A identificação de tecnologias e a definição do sistema de tratamento de efluentes devem seguir o roteiro abaixo, conforme descrito pela Fiesp/Ciesp (2004):

- Identificação, quantificação e caracterização de todas as correntes de efluentes geradas;

- Avaliação do aproveitamento de correntes específicas de efluentes para aplicação da prática de reúso em cascata;

- Verificação da necessidade de segregação de correntes específicas de efluentes, as quais podem requerer um tratamento exclusivo;

- Identificação de tecnologias com potencial para o tratamento dos efluentes identificados;

- Desenvolvimento de ensaios de tratamento ou consulta a fornecedores especializados, para verificar o potencial de utilização das tecnologias identificadas;

- Estruturação do sistema coleta, transporte e tratamento dos efluentes.

A tabela 2 mostra as principais técnicas de tratamento, resumido pelo Sistema Fiesp/Ciesp (2004) em parceria com a ANA - Agência Nacional de Águas, buscando a excelência do conhecimento do CIRRA - Centro Internacional de Referência em Reúso de Água e com o suporte da DTC Engenharia. Nesta tabela observamos que não há preferência 
por tecnologia bem como não apresenta as inovações mais recentes aplicadas ao tratamento de efluentes. Por outro lado, coloca aplicações duvidosas, como nitrificação para redução de ferro e de óleos e graxas, bem como não define os parâmetros de o que é eficaz e não eficaz.

\section{Reúso e as Tecnologias Aplicadas na Indústria Têxtil}

Os efluentes secundários de uma indústria de tingimento e de acabamento foram investigados por Lin e Chen (1997) para um possível reúso. Eles abordaram neste estudo a aplicação dos processos: eletroquímico, coagulação química e troca de íon. $\mathrm{O}$ método eletroquímico e o de coagulação química foram aplicados para remover a cor, turbidez (NTU) e reduzir parte da demanda química de oxigênio (DQO), enquanto que a troca de íons foi empregada para abaixar mais a DQO e reduzir a concentração dos íons de ferro, a condutividade e a dureza total. No teste eletroquímico foram empregados eletrodos paralelos de $\mathrm{TiO}_{2}$, com uma área de $22,6 \mathrm{~cm}^{2}$, uma cuba de $1,0 \mathrm{~L}$ e o $\mathrm{pH}$ foi ajustado para 7,0. Para aumentar a eficiência do processo eletroquímico, pequenas quantidades de peróxido de hidrogênio $(200 \mathrm{mg} / \mathrm{L})$ foram adicionadas. Como coagulante foi usado o cloreto de alumínio, a uma concentração de $100 \mathrm{mg} / \mathrm{L}$ e $1,0 \mathrm{mg} / \mathrm{L}$ para um polímero. Para o teste de troca iônica foram usadas resinas catiônica Ambersep 132, tipo H, e aniônica Ambersep 900, tipo OH cujo melhor resultado alcançado foi de uma relação catiônica/aniônica igual a 2. Resultados experimentais ao longo do estudo indicaram uma efetiva redução da cor (90\%), da turbidez, da DQO (80\%), da condutividade e da dureza total. Eles concluíram que os métodos de tratamento químicos combinados são muito efetivos e são capazes de elevar a qualidade de água do efluente, que poderá ser reusada na indústria.

\begin{tabular}{|c|c|c|c|c|c|c|c|c|}
\hline \multirow[b]{2}{*}{ VARIÁVEIS } & \multicolumn{8}{|c|}{ Técnicas de Tratamento } \\
\hline & $\begin{array}{c}\text { Tratamento } \\
\text { Primário }\end{array}$ & $\begin{array}{c}\text { Lodos } \\
\text { Ativados }\end{array}$ & $\begin{array}{l}\text { Nitrifi- } \\
\text { cação }\end{array}$ & $\begin{array}{c}\text { Desnitri- } \\
\text { ficação }\end{array}$ & $\begin{array}{c}\text { Filtro } \\
\text { Biológico }\end{array}$ & Biodisco & $\begin{array}{c}\text { Coagulação } \\
\text { Floculação } \\
\text { Sedimentação }\end{array}$ & $\begin{array}{c}\text { Stripping } \\
\text { da amônia }\end{array}$ \\
\hline DBO & B & E & $\mathrm{E}$ & $\mathrm{NE}$ & $\mathrm{E}$ & $\mathrm{E}$ & E & $\mathrm{NE}$ \\
\hline DQO & B & E & E & E & E & & E & $\mathrm{NE}$ \\
\hline SST & $\mathrm{E}$ & E & E & $\mathrm{NE}$ & E & E & E & $\mathrm{NE}$ \\
\hline $\mathrm{NH}_{3}-\mathrm{N}$ & $\mathrm{NE}$ & E & E & B & & E & $\mathrm{NE}$ & E \\
\hline $\mathrm{NO}_{3}-\mathrm{N}$ & & & & E & & & $\mathrm{NE}$ & $\mathrm{NE}$ \\
\hline Fósforo & $\mathrm{NE}$ & B & E & E & & & E & $\mathrm{NE}$ \\
\hline Alcalinidade & & B & & & & & B & $\mathrm{NE}$ \\
\hline Óleos e Graxas & E & E & E & & & & B & $\mathrm{NE}$ \\
\hline Arsênio & B & B & B & & & & B & $\mathrm{NE}$ \\
\hline Bário & & B & $\mathrm{NE}$ & & & & B & $\mathrm{NE}$ \\
\hline Cádmio & B & E & $\mathrm{E}$ & & NE & B & E & $\mathrm{NE}$ \\
\hline Cromo & B & E & $\mathrm{E}$ & & $\mathrm{NE}$ & E & E & $\mathrm{NE}$ \\
\hline Cobre & B & E & $\mathrm{E}$ & & $\mathrm{E}$ & E & E & $\mathrm{NE}$ \\
\hline Flúor & & & & & & & B & $\mathrm{NE}$ \\
\hline Ferro & B & E & $\mathrm{E}$ & & B & E & E & $\mathrm{NE}$ \\
\hline Chumbo & E & E & $\mathrm{E}$ & & B & E & E & $\mathrm{NE}$ \\
\hline Manganês & NE & B & B & & $\mathrm{NE}$ & & B & $\mathrm{NE}$ \\
\hline Mercúrio & $\mathrm{NE}$ & $\mathrm{NE}$ & $\mathrm{NE}$ & & $\mathrm{NE}$ & E & $\mathrm{NE}$ & $\mathrm{NE}$ \\
\hline Selênio & $\mathrm{NE}$ & $\mathrm{NE}$ & $\mathrm{NE}$ & & & & $\mathrm{NE}$ & $\mathrm{NE}$ \\
\hline Prata & E & E & E & & B & & E & $\mathrm{NE}$ \\
\hline Zinco & B & B & $\mathrm{E}$ & & E & E & E & $\mathrm{NE}$ \\
\hline Cor & NE & B & B & & NE & & E & \\
\hline
\end{tabular}




\begin{tabular}{llllllll}
\hline Substâncias & B & E & E & & E & B & \\
Tensoativas & B & E & E & NE & B & E & \\
Turbidez & B & E & E & NE & B & E & NE \\
COT &
\end{tabular}

Tabela 2 - Principais Técnicas de Tratamento

$\mathrm{E}=$ Eficaz (Remoção completa ou quase total)

$\mathrm{NE}=$ Não eficaz (Baixa remoção ou ineficaz)

$\mathrm{B}=$ Bom (Remoção de grandes porcentagens)

As células em branco denotam insuficiência de dados, resultados não conclusivos ou aumento da concentração.

Lopez et al (1999) estudaram as águas residuárias do tratamento secundário e do biológico, contendo uma DQO de 595 ppm e carbono orgânico total (COT) de 190 ppm. Aplicando um tratamento com ozônio, 12 ppm por 120 minutos, a $\mathrm{DBO}_{5}$ aumentou de zero para $75 \mathrm{ppm}$, enquanto que a DQO e o COT reduziram $50 \%$ e $30 \%$, respectivamente. Quanto aos poluentes potencialmente tóxicos e inibitórios como: as tinturas, os sulfactantes não iônicos e halogenados orgânicos. Todos os seus parâmetros foram medidos como soma. Remoções desses poluentes, maiores que $90 \%$, foram alcançadas e confirmadas pelo desaparecimento completo de toxicidade aguda. Os únicos subprodutos da ozonização, pesquisados e encontrados, foram aldeídos, cuja quantidade aumentou continuamente na primeira hora de 1,2 até 11,8 ppm. Entre eles foram identificados, por HPLC, o formaldeído, acetaldeído, glioxal, propanaldeído e butiraldeído.

Bergna, Bianchi e Malpei (1999) apresentaram os resultados de laboratório e de escala piloto obtidos na aplicação do processo de adsorção de carbono ativado granular, sobre efluentes de acabamentos têxteis que requerem restrições da DQO e da remoção de cor. Os testes em laboratório comprovaram a capacidade de adsorção de carbono específica para DQO, sendo a intensidade da cor mais alta para o efluente passado em um filtro de areia, seguida de uma clarifloculação. Já os resultados obtidos para os efluentes secundários tratados em filtro de areia e por ozonização foram menores. Eles também executaram testes em escala piloto e a performance de três filtros com volume de $0.3,3$ e $20 \mathrm{~m}^{3}$ de carbono ativo granular (GAC), cada um alimentado com efluente secundário ozonizado foram apresentados.

Estudos usando processos físicos e químicos para redução da DQO e da cor de efluente de diferentes fábricas de tingimento foram realizados por Li e Zhao (1999). Um dos efluentes testados tinha característica ácida e o outro considerado normal. $\mathrm{O} \mathrm{pH}$ foi ajustado para faixa de 7,0 a 8,0. Eles usaram um processo fotocatalítico na presença de $\mathrm{TiO}_{2}$, formando uma lama com $10 \mathrm{~g}$ do óxido para cada $100 \mathrm{~mL}$ do efluente, depois de ser submetido ao ultrasom por 15 minutos. Para degradar diferentes substâncias químicas, o efluente passou pelo reator biológico, de Aeração Intermitente Estendida Decantada, usando um lodo com idade de 10 dias e com um tempo de retenção hidráulica de 1,5 dias. Em seguida foi submetido a uma filtragem (filtro de areia) e ao tratamento fotocatalítico e, finalmente, passado em um filtro de membrana. A areia empregada tinha uma granulometria de $0,3-1,0 \mathrm{~mm}$ e o filtro de areia funcionou com uma vazão de $140 \mathrm{~L} / \mathrm{m}^{2} \mathrm{~min}$. O reator fotocatalítico usado tinha um volume de 1,1 L, com uma lâmpada de UV de $20 \mathrm{~W}(365 \mathrm{~nm})$ e com 4 difusores de ar na base. Porém, para separar eficientemente e reusar, continuamente, a suspensão de $\mathrm{TiO}_{2}$ do efluente tratado, passou o efluente pelo processo de microfiltração, usando uma membrana Millipore com 47 mm de diâmetro, a uma pressão de 0,29 - 0,59 bar aplicada conforme o tamanho do poro. A cor aumentou de 6,3 para 25,4 (unidade Lovibond) para o efluente normal e reduziu de 38,1 para 10 no efluente ácido. A DQO foi removida de $44,7 \%$ para o efluente normal e $68,1 \%$

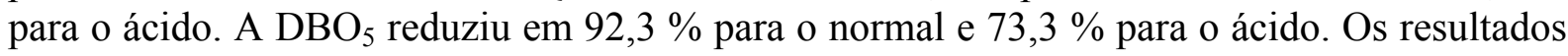
demonstraram que o processo de oxidação fotocatalítica degrada as substâncias orgânicas não biodegradáveis e a microfiltração foi eficiente para os efluentes tratados após processo 
biológico. A qualidade da água obtida, por esses processos, apresentou ser compatível para o reúso.

Um efluente após passar por um tratamento de lodo ativado e filtro de areia, foi submetido a uma ultrafiltração seguida de osmose reversa, a 8 bar de pressão e numa vazão de $800 \mathrm{~L} / \mathrm{h}$, foi testada em escala piloto por Ciardelli, Corsi e Marcucci (2000). Na etapa de ultrafiltração foi usada uma membrana, em modo espiral, tipo Trisep 8040-UE50-TXA, revestida com fibra de vidro, com uma área de filtragem de $23 \mathrm{~m}^{2}$, uma pressão de 4 bar, com uma vazão de $500 \mathrm{~L} / \mathrm{h}$ e com capacidade de reter substâncias até $100 \mathrm{kDa}$. A osmose reversa foi composta por dois módulos de membranas de poliamida, tipo Toray, em espiral, colocadas em série e com uma área de $54 \mathrm{~m}^{2}$ cada. Aplicou-se uma vazão de $500 \mathrm{~L} / \mathrm{h}$ e uma pressão de 8 bar, onde $60 \%$ foi permeado e o restante foi descartado. Eles observaram que o filtro de areia retém cerca de $95 \%$ dos sulfactantes aniônicos. A filtragem em areia seguida da ultrafiltração fez a remoção total dos sólidos em suspensão e a turbidez teve uma redução de $95 \%$. Variações nos parâmetros hidráulicos não foram observados durante a osmose reversa, indicando a ausência de entupimento da membrana. Com a osmose reversa foram alcançadas uma redução de $95 \%$ dos sais e dos compostos orgânicos. Também a DQO e a cor tiveram uma redução de praticamente $100 \%$. Eles concluíram que o permeado da osmose reversa tem boas características físico-quimicas (remoção quase total de sais e do conteúdo orgânico) e que poderá ser reusado em todos os processos da indústria têxtil, até mesmo nas mais exigentes, como no tingimento de fios de lã ou de cores claras. A água obtida apresentou qualidade melhor do que a do consumo normal, o que propicia o seu reúso no processo.

Diferentes processos de membrana foram experimentados em escala piloto por Marcucci et al (2001), com objetivo de verificar a possibilidade de reúso das águas residuárias de uma indústria. O efluente após passar por um filtro de areia e seguido de uma nanofiltração, tipo Osmotic Desal DL 4040F para reter compostos 150 - $300 \mathrm{Da}$ a uma pressão de 9 bar, foi comparada com a osmose reversa, tipo Filmtec TW30-LE 4040 com poder de retenção não definido e 13 bar de pressão. Ambas foram testadas no formato espiral, para favorecer a turbulência e, por conseguinte, reduzir a sujeira. Outra técnica usada por eles foi da ultrafiltração, utilizando um modulo FLAMEC (FLAt MEmbrane Cassette), constituída de fluoreto de polivinilideno, com área de $66 \mathrm{~m}^{2}$, capacidade de retenção até $70.000 \mathrm{Da}$ e operada com vácuo de 0,4 bar. A vazão do efluente após filtro de areia foi de $1200 \mathrm{~L} / \mathrm{h}$. A água obtida pela osmose reversa, teve uma redução quase total da DQO e $93 \%$ da cor, poderia ser reutilizada no processo de tingimento de fios, enquanto que a produzida pela nanofiltração não apresentou qualidade suficiente para tal. A remoção da dureza alcançada pela aplicação da osmose reversa foi de $95 \%$ e pela nanofiltração não ultrapassou $75 \%$.

Ciardelli e Ranieri (2001) testaram, em escala piloto, um efluente após passar pelo tratamento biológico, seguido de uma filtração em filtro de areia, antes de passar pelo processo de ozonização e/ou de eletrofloculação. A ozonização foi efetuada para uma vazão de $250 \mathrm{~L} / \mathrm{h}$ de efluente e com uma taxa de injeção de $40 \mathrm{~g} / \mathrm{m}^{3}$ de ozônio. A remoção da cor alcançou resultados de 95 - 99\%, enquanto que a DQO reduziu em $67 \%$, de onde foi possível a sua reutilização na unidade de tingimento de fios da indústria têxtil. Neste teste, a DQO atingiu valores de $75-120 \mathrm{mg} / \mathrm{L}$, considerados altos para o setor de tingimento. Para o teste da eletrofloculação foram usados duas células, alternadas com eletrodo de ferro ou alumínio, alimentados com uma corrente de 40 - 60 A e para uma vazão de $2 \mathrm{~m}^{3} / \mathrm{h}$. A água resultante apresentou uma redução de cor entre 84 a $94 \%$ e da DQO variou de 51 a $81 \%$, dependendo da origem do efluente. Eles observaram uma pequena redução dos íons cloretos e sulfatos e constataram que o hidrogênio produzido ajudou na floculação do lodo. Após a eletrofloculação, foi aplicada uma oxidação do ferro na segunda célula, seguida de uma flotação. A redução da cor chegou a 100 \%. A água gerada desse processo pode ser reusada no setor de tingimento. 
Estudos realizados em escala piloto por Ciardelli, Capannelli e Bottino (2001) em efluentes oriundos do tratamento biológico, misturados com efluente gerado na unidade de tingimento. Neste estudo foi usado um sistema de difusão de ozônio através de uma membrana tubular, Akzo Nobel ou FCT-US Filter. Eles passaram o efluente por um filtro de areia, em PVC de $0,076 \mathrm{~m}^{3}$ antes da ozonização. O ozônio foi produzido em um gerador, Degremont, com capacidade de $50 \mathrm{~g} \mathrm{O}_{3} / \mathrm{h}$. A taxa de injeção variou de 20 a $50 \mathrm{~g} / \mathrm{m}^{3}$ do efluente. O tempo de contato foi de 15, 30 e 60 minutos. As vazões do efluente testada foram de 125,250 e $500 \mathrm{~L} / \mathrm{h}$. Os melhores resultados foram com uma taxa de $\mathrm{O}_{3}$ de $30 \mathrm{~g} / \mathrm{m}^{3}$ para um tempo de 60 minutos e $40 \mathrm{~g} / \mathrm{m}^{3}$ para 30 minutos. A taxa de remoção da cor foi de $95-99 \%$ e a redução da DQO chegou a 60\%. A qualidade da água obtida foi compatível para o reúso em outros processos.

$\mathrm{O}$ efeito do tratamento químico em um efluente oriundo do tratamento biológico, gerado por pequenas empresas de tingimento de algodão, nylon, poliéster, foi investigado por Dulkadiroglu et al (2002). Eles usaram amostras dos efluentes onde representavam $68 \%$ da geração, oriunda de 7 diferentes processos. Uma segunda amostra representando $55 \%$ dos efluentes gerados, provenientes de 4 processos produtivos também foi usada, bem como uma terceira amostra coletada em um tanque de equalização do sistema de tratamento de efluentes. Como coagulante foi empregado, em concentrações variadas, $\mathrm{FeCl}_{3}, \mathrm{Ca}(\mathrm{OH})_{2}, \mathrm{Al}_{2}\left(\mathrm{SO}_{4}\right)_{3}$, bentonita e um polieletrólito aniônico. A bentonita usada removeu a DQO solúvel juntamente com a cor e os componentes particulados. Eles observaram que o tratamento químico com bentonita, quando aplicado antes do tratamento biológico, remove cerca de $40 \%$ dos biodegradáveis bem como os solúveis inertes da DQO presentes. Essa observação foi de grande importância no ponto de vista da DQO residual. No efluente de lodo ativado foi incluída uma quantidade significante de produtos metabólicos, não biodegradáveis gerados, em proporção à quantidade de substrato utilizado. Aplicando um pós-tratamento químico, como uma etapa de polimento, houve a remoção dos particulados e, numa menor quantidade, a DQO remanescente, cerca de $20 \%$. Estes resultados sugeriram que um pré-tratamento químico é uma alternativa para melhorar a remoção da DQO solúvel. Já o pós- tratamento químico seria uma etapa de polimento para remover os particulados e parte da DQO solúvel.

Bes-Piá et al (2002), usando equipamento de jar teste, realizaram tratamento físicoquímico seguido de processo de filtração em membrana. Eles puderam comparar a eficiência da nanofiltração com a ultrafiltração em um efluente. Como coagulante foi empregado $\mathrm{FeCl}_{3}$ e/ou $\mathrm{Al}_{2}\left(\mathrm{SO}_{4}\right)_{3}$ numa concentração de $200 \mathrm{mg} / \mathrm{L}$ e um agente floculante aniônico na razão de $1 \%$. O pH ótimo encontrado foi de 8,5 e seu controle foi pela adição de $\mathrm{NaOH} 0,1 \mathrm{~N}$ ou $\mathrm{HCl}$ 0,1 N. As membranas usadas para a ultrafiltração tinham poder de retenção de 5,40 e 100 Kda e uma pressão operacional de 0,0015 bar. Foi aplicada uma vazão de $40 \mathrm{~L} / \mathrm{h}$ a $20^{\circ} \mathrm{C}$. Para a nanofiltração, as membranas usadas apresentaram uma permeabilidade de 0,0219 - 0,2309 $\mathrm{m}^{3} / \mathrm{h}$, numa vazão de $400 \mathrm{~L} / \mathrm{h}$, com uma área de filtragem de $0,009 \mathrm{~m}^{2}$ e pressão de 0,0098 bar a $20{ }^{\circ} \mathrm{C}$. Durante o processo físico-químico, a redução da DQO foi $50 \%$. Enquanto que o melhor resultado alcançado com as membranas foi com a nanofiltração, onde a DQO ficou abaixo de $25 \mathrm{mg} / \mathrm{L}$ e apresentou uma condutividade na faixa de $0,5-1,1 \mathrm{mS} / \mathrm{cm}$.

A aplicação da combinação usando processos físico-químicos com a nanofiltração pode estudar a qualidade da água gerada em uma indústria têxtil. Neste caso, Bes-Piá et al (2003), em escala piloto, usaram membranas com permeabilidade de $0,481-3,863 \mathrm{~L} / \mathrm{m}^{2} \mathrm{~h}$. Como coagulante foram usadas soluções de $\mathrm{Al}_{2} \mathrm{O}_{3}$ e sais de $\mathrm{Fe}^{2+}$, em diferentes concentrações e pH. Após 30 minutos de decantação eles realizaram os ensaios de DQO, condutividade elétrica e $\mathrm{pH}$. As vazões variaram de $0,2-0,4 \mathrm{~m}^{3} / \mathrm{h}$, a pressão aplicada oscilou de 0,0010 a 0,0020 bar. O melhor resultado obtido foi quando aplicou uma concentração de $700 \mathrm{mg} / \mathrm{L}$ de $\mathrm{Fe}^{2+}$, em pH 12,0, independente da membrana. Para uma vazão de $200 \mathrm{~L} / \mathrm{h}$ e uma pressão de 20 bar, a redução da DQO efetiva foi de $72,5 \%$ ou seja, apresentou valores abaixo de 100 
$\mathrm{mg} / \mathrm{L}$. Nestas condições, a condutividade alcançou $0,48 \mathrm{mS} / \mathrm{cm}$ o que representou uma redução de 90\%. Quanto a retenção de sais, oscilou de 85 - $90 \%$, para uma taxa de fluxo do permeado de $8-10 \mathrm{~L} / \mathrm{m}^{2}$.h. Portanto, eles concluíram que o resultado depende da pressão aplica na alimentação.

O desempenho da oxidação química avançada para eliminar a cor, demanda bioquímica de oxigênio após 5 dias $\left(\mathrm{DBO}_{5}\right)$ e DQO, a jusante de um bioreator de membrana (MBR) foi testado por Brik et al (2004). Três diferentes tipos de oxidação, foram avaliadas em escala de laboratório: ozonização, cloração e adição do peróxido de hidrogênio. O ozônio usado foi gerado a uma concentração de $20 \mathrm{~g} / \mathrm{m}^{3}$, para uma vazão de $15 \mathrm{~L} / \mathrm{h}$. Medições na entrada e saída do reator foram realizadas. O excesso de ozônio foi absorvido em KI. A cloração e a adição de peróxido foram realizadas em um jar teste, onde concentrações de 10 , 130 e $250 \mathrm{mg} / \mathrm{L}$ foram usadas. Diferentes velocidades de agitação foram aplicadas, 40, $120 \mathrm{e}$ $200 \mathrm{rpm}$ por uma hora. Eles observaram que quando se aplicava $250 \mathrm{mg} / \mathrm{L}$ de cloro ativo, só $80 \%$ da cor foi removida. Este resultado foi considerado insatisfatório. Para o peróxido de hidrogênio, a remoção da cor foi insignificante, cerca de $10 \%$, quando foi aplicada uma concentração de $250 \mathrm{mg} / \mathrm{L}$. Em contraste, os resultados obtidos através de ozonização foram bons. Quando se usou uma concentração ozônio de $38 \mathrm{mg} / \mathrm{L}$, durante 20 minutos, a remoção da cor alcançou uma eficiência de $93 \%$. Por outro lado, a DQO aumentou porque a ozonização não oxidou completamente os compostos orgânicos, mas houve apenas a quebra de algumas moléculas. Contudo, eles recomendaram tal procedimento como um prétratamento antes do bioreator de membrana ou como um processo de polimento final.

$\mathrm{O}$ tratamento de águas residuárias usando a oxidação eletroquímica combinada com uma filtração em membrana de transferência de fluxo foi estudada por Chen et al (2005), com objetivo de reúso. Eles usaram eletrodos de titânio galvanizado com $\mathrm{PbO}_{2}$, como anodo e uma barra de aço inox, nas mesmas dimensões, como catodo. A membrana foi montada na forma de arco, com finalidade de aumentar a área filtrante e sua resistência mecânica. A oxidação eletroquímica foi efetuada em um reator de 1,2 L. Durante a eletrólise foi aplicada um diferencial de potencial de $8 \mathrm{~V}$ e a corrente elétrica foi mantida em $124 \mathrm{~A} / \mathrm{m}^{2}$. Depois da eletrólise, DQO e a cor da solução foram analisadas. Eles observaram que para a seqüência, eletrólise seguida da filtração, a redução da cor foi de $91 \%$ e da DQO foi de $90 \%$. Mudando a seqüência para filtração seguida da eletrólise, a redução da cor foi de $85 \%$ e da DQO foi de 86 $\%$. Segundo eles, esta diferença foi devido à filtração reduzir o teor dos sólidos suspensos. Concluíram ainda que a oxidação eletroquímica remove a cor da água residuária efetivamente, enquanto que o filtro de membrana remove quase que totalmente os sólidos solúveis. Portanto, a água tratada obtida pode ser reutilizada em muitas áreas de produção da fábrica.

\section{CONSIDERAÇÕES FINAIS}

Através do presente trabalho, constatamos que existem várias tecnologias que podem ser utilizadas no tratamento de efluentes. Sua escolha e combinação dependem qual o objetivo do tratamento. Pois os processos oxidativos quando aplicados de maneira isolada não apresentam boa eficiência. É importante salientar que os sistemas oxidativos homogêneos empregados após um tratamento convencional, biológico ou físico-químico, apresentaram elevada eficiência. Por outro lado, sistemas associados a uma fonte de radiação ultravioleta ou visível, tipo radiação solar, consegue obter altas taxas de mineralizações em curto intervalo de tempo.

Dois fatores devem ser observados quanto a escolha da tecnologia a ser aplicada: 
- primeiro: é conhecer as características físico-química do efluente, objeto do tratamento,

- segundo: é saber qual deverá ser a aplicação da água obtida após tratamento. Melhores resultados serão alcançados quando houver a conjugação de tecnologia.

Contudo, não devemos esquecer que existe uma legislação a ser atendida para o descarte das águas residuárias. Portanto, deve-se esperar, a priori, que a combinação das tecnologias poderá apresentar as soluções cabíveis, no tratamento de efluentes que atendam a legislação.

No entanto, podemos afirmar que num futuro bem próximo haverá mais tecnologias que atendam as necessidades das empresas, o que possibilitará o aumento do reúso de suas águas residuárias.

Por fim, podemos dizer que o reúso e a conservação da água hoje se constituem em palavras-chaves da gestão dos recursos hídricos. Por outro lado, a prática de reúso de água espera ser institucionalizada e integrada aos planos de proteção e desenvolvimento das bacias hidrográficas. 


\section{Referências Bibliográficas}

ABDESSEMED, D. and NEZZAL, G. - Treatment of Primary Effluent by Coagulation Adsorption - Ultrafiltration for Reuse. Desalination, vol. 152, p. 367 - 373, 2002.

ADIN, A. Particle Characteristic: A Key Factor in Effluent Treatment and Reuse. Water Science and Technology, vol. 40, issue 4 - 5, p 67 - 74, 1999.

BERGNA, G.; BIANCHI, R. and MALPEI, F. - GAC Adsorption of Ozonated Secondary Textile Effluents for Industrial Water Reuse. Water Science and Technology, vol. 40, issue $4-5$, p $435-442,1999$.

BES-PIÁ, A.; MENDOZA-ROTA, J.A.; ALCAINA-MIRANDA, M.I. IBORRA-CLAR, A. and IBORRA-CLAR, M.I.. - Reuse of wastewater of the textile industry after its treatment with a combination of physico-chemical treatment and membrane technologies, Desalination, vol. 149, p. $169-174,2002$.

BES-PIÁ, A.; MENDOZA-ROTA, J.A.; ALCAINA-MIRANDA, M.I. IBORRA-CLAR, A. and IBORRA-CLAR, M.I.. - Combination of physico-chemical treatment and nanofiltration to reuse wastewater of a printing, dyeing and finishing textile industry. Desalination, vol. 157, p. $73-80,2003$.

BOUSSELMI, L.; GEISSEN, S. U. and SCHROEDER, H. - Textile wastewater treatment and reuse by solar catalysis: results from a pilot plant in Tunisia; Water Science and Technology, vol. 49, issue 4, p 331 - 337, 2004.

BRIK M, CHAMAM B, SCHOBERL P, BRAUN R and FUCHS W. - Effect of ozone, chlorine and hydrogen peroxide on the elimination of colour in treated textile wastewater by MBR. Water Science and Technology, vol. 49, issue 4, p. 299 - 303, 2004.

CHEN, X.; SHEN, Z.; ZHU, X.; FAN, Y. and WANG, W.. - Advanced treatment of textile wastewater for reuse using electrochemical oxidation and membrane filtration; Water SA, vol. 31, No. 1, p $127-133,2005$.

CIARDELLI, G. and RANIERI, N. - The treatment and reuse of wastewater in the textile industry by means of ozonation and electroflocculation. Water Research, vol. 35 issue 2, p. $567-572,2001$.

CIARDELLI, G.; CORSI, L. and MARCUCCI, M. - Membrane separation for wastewater reuse in the textile industry. Resources, Conservation and Recycling, vol. 31, issue 2, p. $189-197,2000$.

CIARDELli,G.; CAPANNELLI, G. e BOTTINO, A. - Ozone treatment of textile wastewaters for reuse. Water Science and Technology, vol 44, issue 5, p 61 - 62, 2001.

CONAMA - Resolução Conama nº 357 - de 17 de março de 2005.

DULKADIROGLU, H.; DOGRUEL, S.; OKUTMAN, D.; KABDASL, I.; SOZEN, S. and ORHON, D.. - Effect of Chemical Treatment on Soluble Residual COD in Textile Wastewater. Water Science and Technology, vol. 45, issue 12, p 251 - 259, 2002. 
FIESP/CIESP - Conservação e Reúso de Água para Indústria, Manual de Orientações para o Setor Industrial, vol 1, 90p., 2004.

GOGATE, P.R. and PANDIT, A.B..- A Review of Imperative Technologies for Wastewater Treatment I: Oxidation Technologies at Ambient Conditions, Advances in Environmental Research, vol. 8, p501 - 551, 2004.

HESPANHOL, I. - Potencial de Reúso de Água no Brasil - Agricultura, Indústria, Municípios, Recarga de Aqüíferos, disponível em http://www.aguabolivia.org/situacionaguaX/IIIEncAguas/contenido/trabajos_verde/TC-

158.htm, acessado em 21/06/2004.

LIN, S.H. and CHEN, M. I. - Treatment of textile wastewater by chemical methods for reuse. Water Research, vol. 31, issue 4, p. 868 - 876, 1997.

LI, X. Z. e ZHAO, Y. G. - Advanced Treatment of Dyeing Wastewater for Reuse. Water Science and Technology, vol. 39 issue $10-11$, p. $249-255,1999$.

LOPEZ, A.; RICCO, G., R.; CIANNARELLA; ROZZI, A.; DI PINTO, A. C. and PASSINO, R. - Textile Wastewater Reuse: Ozonation of Membrane Concentrated Secondary Effluent; Water Science and Technology, vol. 40 issue 4-5, p. $99-105,1999$.

MADWAR, K. and TARAZI, H. - Desalination techniques for industrial wastewater reuse; Desalination, vol. 152, issues 1-3, p 325 - 332, 2003.

MANCUSO, P. C. S. e SANTOS, H. F. - Reúso de Água, Ed. Manole Ltda. 579p., 2003

MARCUCCI, M. e TOGNOTTI, L. - Reuse of wastewater for industrial needs: the Pontedera case, Resources, Conservation and Recycling, vol. 34, p 249 - 259, 2002.

MARCUCCI, M.; NOSENZO, G.; CAPANNELLI, G.; CIABATT, I.; CORRIERI, D. and CIARDELLI, G. - Treatment and reuse of textile effluents based on new ultrafiltration and other membrane technologies. Desalination, vol. 138, p. 75 - 82, 2001.

MARTINS, G. e ALMEIDA, J. C. V. - Reúso e Reciclo de Águas em Industria Química de Processamento Dióxido de Titânio, monografia apresentada no curso de especialização em Gerenciamento e Tecnologias Ambientais na Indústria. Escola Politécnica, Universidade Federal da Bahia, UFBa, 69p.1999.

MIRBAGHERI, S.A. and HOSSEINI, S.N. - Pilot plant investigation on petrochemical wastewater treatment for the removal of copper and chromium with the objective of reuse; Desalination, vol.171, issue 1, p 85 - 93, 2005.

MOHSEN, M.,S. - Treatment and reuse of industrial effluents: Case study of a thermal power plant, Desalination, issue 167, p 75 - 86, 2004.

MOHSEN, M.,S. and JABER, J.,O. - Potential of industrial wastewater reuse. Desalination, vol. 152, issues 1-3, p $281-289,2002$. 
MUJERIEGO, R. and ASANO, T. - The Role of Advanced Treatment in Wastewater Reclamation and Reuse. Water Science and Technology, vol. 40, issue 4 - 5, p 1 - 9, 1999.

PASCAL, F. M. M. e TREMILIOSE-FILHO, G. - Aplicação da Tecnologia de Eletrofloculação na Recuperação do Corante Índigo Blue a partir de Efluentes Industriais. Química. Nova, vol. 28, nº. 5, p 766 - 772, 2005.

ROUSE, M. - International Water Association, no Fórum Internacional das Águas, Porto Alegre (RS), 2003, Disponível em www.ambientebrasil.com.br, acessado em 10/10/2003.

SAHA, N., K.; BALAKRISHAM, M. and BATRA, V.,S. - Improving industrial water use: case study for an Indian distillery - Resources, Conservation and Recycling, vol. 43, p 163 $-174,2005$.

SCHNEIDER, R., P. e TYSUTIYA, M., T. - Membranas Filtrantes para o Tratamento de Água, Esgoto e Água de Reúso. Associação Brasileira de Engenharia Sanitária e Ambiental, $1^{\mathrm{a}}$ Ed. 233p., 2001.

SUTHANTHARARAJAN, R., RAVINDRANATH, E., CHITRA, K., UMAMAHESWARI, B., RAMESH, T. and RAJAMANI, S. - Membrane application for recovery and reuse of water from treated tannery wastewater; Desalination, vol. 164, p 151 - 156, 2004.

von SPERLING, M. - Princípios do Tratamento Biológico de Águas Residuárias, vol 4, Ed. FCO, 428p., 2002.

YALCIN, F. KOYUNCU, I. OZTURK, I. and TOPACIK, D. - Pilot Scale UF and RO Studies on Water Reuse in Corrugated Board Industry. Water Science and Technology, vol 40, issue $4-5$, p $303-310,1999$.

YOU, S., H.; TSENG, D., H.; GUO, G., L. and YANG, J., J.. - The potential for the recovery and reuse of cooling water in Taiwan. Resources, Conservation and Recycling, vol. 26, issue 1, p. $53-70,1999$.

ZBONTAR, L. and GLAVIC, P. - Total site: Wastewater minimization; Wastewater reuse and Regeneration reuse; Resources, Conservation and Recycling, vol. 30, issue 4, p 261 $275,2000$.

\section{Informações bibliográficas:}

Conforme a NBR 6023:2002 da Associação Brasileira de Normas Técnicas (ABNT), este texto científico publicado em periódico eletrônico deve ser citado da seguinte forma: GUERRA FILHO, D. . Águas Residuárias: uma Alternativa Racional de Reúso. Cadernos UniFOA, Volta Redonda, ano 1, $\mathrm{n}^{\circ} .1$, jul. 2006. Disponível em:

$<$ http://www.unifoa.edu.br/pesquisa/caderno/edicao/01/17.pdf $>$ 